\title{
A Comprehensive Analysis of Cloud based Big Data Challenges and Opportunities for SMEs in India
}

Nitirajsingh Sandu ${ }^{*}$, Canterbury Institute of Management, 41 McLaren St, North Sydney, Australia

Ergun Gide, Central Queensland University, 400 Kent Street, Sydney, Australia

Shakir Karim, Central Queensland University, 400 Kent Street, Sydney, Australia

\section{Suggested Citation:}

Sandu, N., Gide, E., Karim, S., (2020). A Comprehensive Analysis of Cloud based Big Data Challenges and Opportunities for SMEs in India. Global Journal of Information Technology: Emerging Technologies. 10(1), 35-44. DOI: $\underline{10.18844 / \text { gjit.v\%vi\%i.4745 }}$

Received from January 10, 2020; revised from February 20, 2020 ; accepted from 20 April, 2020.

Selection and peer review under responsibility of Prof. Dr.Doğan Ibrahim, Near East University, Cyprus.

${ }^{\circ}$ 2020. Birlesik Dunya Yenilik Arastirma ve Yayincilik Merkezi, Lefkosa, Cyprus

\begin{abstract}
The purpose of this paper is to do a comprehensive analysis of Cloud based Big Data challenges and opportunity for SMEs in India. Big Data (BD) are big buzz words, and many large enterprises are making significant advances in their product development, customer relations, and increasing profitability by targeting specific customers. Therefore, it has generated interest for both the academic and industry world as it has the potential to enhance the decision making process by providing valuable insights. The large organisations are benefiting from using BD as a tool to gain a competitive edge over rivals by driving new revenue streams and improving internal operational efficiency. The large organisations are already investing as well leveraging BD. On the contrary, Small and Medium Enterprises (SMEs) in India are slow adopters of new technologies due to many factors and pose to lose their competitive edge on the world stage. SMEs can also leverage BD to gain a strategic competitive advantage but are resource poor in terms of investment in manpower and financial resources. Major challenges still exist in the adoption of BD especially in information technology architecture. Cloud Computing (CC) can eliminate the need to maintain expensive computing hardware, software, and networking resources. CC can also provide a solution to scalability issues, high speed performance, and fault tolerance for using BD. With CC usage, SMEs can take advantage of BD without significant investment in information technology and manpower. This research uses secondary data as a research data collection technique, which is its limitation. However, a quantitative research methodology using statistical surveys is planned to be conducted in the near future to understand the factors impacting on the adoption of Cloud based Big Data for Indian SMEs. This paper contributes to exploring and enhancing the understanding of the challenges and opportunities for SMEs in India for adopting BD. This study will also have both industrial implications for practitioners in India, as well as those in other developing countries, and academic implications for researchers who are interested in BD adoption in developing countries.
\end{abstract}

Keywords: Cloud Computing (CC), Big Data (BD), Small and Medium Enterprises (SMEs), Challenges, Opportunities, India.

\footnotetext{
* ADDRESS FOR CORRESPONDENCE: Nitirajsingh Sandu; Canterbury Institute of Management, 41 McLaren St, NORTH SYDNEY, Sydney, Australia

E-mail address: pd.infosystems@ciom.edu.au / Tel.: +61401439579
} 


\section{Introduction}

Big Data (BD) is a combination of transactional and interactive data (Sivarajah, Kamal, Irani, \& Weerakkody, 2017). Interactive data is adding variety and velocity to the ever-growing data reservoir. Understanding customer data poses a significant challenge to SMEs who are facing competition across the globe and are aspiring to become giant in India (Verma \& Bhattacharyya, 2017). BD analytics can help transform existing business models to intelligent businesses by using frameworks. Data can help SMEs to change their existing models as well as help them to diversify in other products or markets (Dua, 2017). BD is revolutionizing the way we explore unstructured data such as email conversations, video content, voice recordings, and social media posts (Kshetri, Fredriksson, \& Torres, 2017). It has the power to transform the way we live, design smarter cities, cure cancer, and operate and improve businesses. Social media consists of people expressing their ideas, recommendations, and likes and dislikes that may help businesses identify customer preferences, partner expectations and needs (Zolkepli \& Kamarulzaman, 2015). From the year 2015, Facebook had approximately 1.05 billion users every day with 206 photos uploaded daily and 125 billion friends connecting (Dhabhai \& Gupta, 2016). For sure, this has created new pathways to research about the cultural and social dynamics of big data on Indian SMEs. People have been wondering how such developments would be transforming or somewhat affecting SME enterprises concerning the opportunities and challenges that big data bears (Rahi, Bisui, \& Misra, 2017).

Compared to the rest of the Asia Pacific (APAC), India Organisations are improving operations and customer service adoption of the latest technologies. BD as a next-gen trend in order to improve customer relationships and operational excellence, is growing rapidly in Indian Organisations (Kulesh, 2018). Furthermore, the author states that in Science, Technology, Engineering and Mathematics (STEM) education, India is the leader and companies are well prepared to leverage BD and analytics. Cloud Computing (CC) has also been rapidly adopted in India. According to a survey conducted by a market research firm, the Cloud strategies of $43 \%$ of businesses are fully implemented and also concluded that businesses that had adopted $70 \%$ or more application on the Cloud platform outperform their competitors on the world stage (Dua, H. s. 2017).

In today's globally connected world, millions of sensors exist across multiple applications, generating stream data for evaluation (Alsghaier, Akour, Shehabat, \& Aldiabat, 2017). Cloud based systems automatically collect this virtual data into various sources in multiple formats (Priyadarshinee, Raut, Jha, \& Kamble, 2017). SMEs in consumer facing sectors such as financial services, hospitality, retail, travel, healthcare and education can benefit by BD. Data is processed after collection to provide actionable insight, which can help SMEs to make informed business decisions (Dua, 2017; Gupta, Misra, Singh, Kumar, \& Kumar, 2017). The quantum of online transactions increasing steadily and resulting in creating more data, will create a terrific opportunity for Indian SMEs. It will enable business leaders to make the right decision at the right time (Vajjhala \& Ramollari, 2016). With the increased focus on digitation and cashless payment, combined with PAN (permanent account number) and Aadhar (unique ID for Indian citizen), BD will enable the government in information discovery. As the Indian economy matures, the government and other sectors including SMEs will move towards adoption of data driven decision- 
making.

\section{LITERATURE REVIEW}

\subsection{Cloud based services}

Every business depends on Information Technology (IT) for the efficient service delivery and costeffective application of technological resources. Modern technologies are adopted to overcome business pressure, and streamline existing procedures and service delivery cost-effectively for ultimate profit wherein the need for the aforementioned aspects is due to the increase in global competition and shifts in the customer expectations (Bagozzi, 2007). With the increase in globalization, most organizations today have a necessity to decrease costs, increase productivity and profitability in order to attain success and retain their competitive position (Alshamaila, Papagiannidis, \& Li, 2013; Lin \& Chen, 2012). CC had the potential to transform how consumers use and store data, and with this new model, organizations can save money, time and effort (Gide \& Sandu, 2015). To offset the high cost of infrastructure, Cloud service providers need enterprises and consumers to adopt Cloud Computing (R. G. Sandu, E.,Karim,S., 2017). In this aspect, the evolution of Information technology gives several positive advantages and effectiveness to various businesses (R. Sandu, Gide,E.,Karim,S., 2017). In the field of information technology, Cloud-based services play a dominant role because of the several advantages, which include easy maintenance, decreased costs and easy re-provisioning of resources that leads to higher profits resource pooling, rapid elasticity, broad network access, etc. (Sharma, AlBadi, Govindaluri, \& Al-Kharusi, 2016). Further, acquiring novel technologies such as Cloud-based services would support numerous organizations in attaining their competitive level and also permit them to become more productive and efficient (Rohani \& Hussin, 2015). Cloud Computing includes three kinds of services: Software as a Service (SaaS), Infrastructure as a Service (laaS) and Platform as a Service (PaaS) (Mell \& Grance, 2011).

\subsection{Big Data}

Nowadays, through the digitization of various processes, there has been an emergence of various platforms in social networks (Zolkepli \& Kamarulzaman, 2015). The blogs, usage of several forms of sensors, adopting digital devices, which are hand-held, and wearable devices together with other forms of unstructured data, are available on internet. The emergence of the digital era has also led to the introduction of different types of data (Khan, Shakil, \& Alam, 2018). The four ' V's governing BD are high volume, high variety, value and high velocity, as shown in Figure 1. Volume associated with big data can reach an incomprehensive proposition with social media sites such as Facebook having more users than the entire population of China. As one of the Big Data dimensions, the Velocity deals with the speed at which data is coming in, with a variety of data such as tweets, images, sensor data big data analysis consisting of variety of data and they provide value to SMEs. 


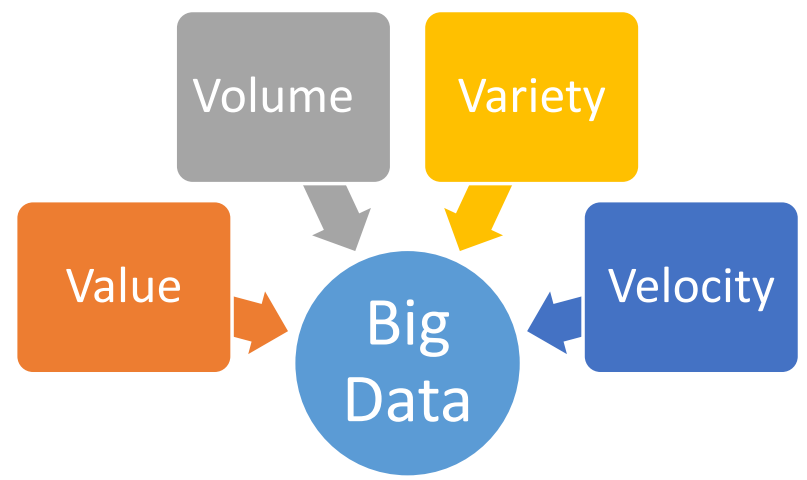

Figure 1 Four Vs of Big data - Adopted from Hashem (2015) (Hashem et al., 2015)

Nobody can repudiate the fact that the internet has brought change in business operations, government functioning, education, as well as the general lifestyle of people globally (Rahi et al., 2017). These days, the trend is that during the transformative stage, the rate of data generation has been high as the created data often surpasses the techniques of storage (Hashem et al., 2015). For the past few years, there has been significant data growth. Between the years 2012 and 2020, there would be a growth by 35 trillion gigabytes of the information attained from the digital universe (Khan \& Alam, 2017). In the middle of the 2000s, cropping up of Cloud Computing, social media, as well as processing power, have led to the rise of Big Data.

\subsection{Small and Medium size Enterprises (SMEs)}

According to a report published by MSME (2017), SMEs contribute about $6 \%$ to India's GDP, with sector contributing $33 \%$ to manufacturing and $45 \%$ to the Indian export sector. It employs more than 80.5 million people. These SMEs can benefit immensely by adopting BD to drive their business forward. It will help developing countries like India to become the global giant it aspires to be with financial inflow to the economy. SMEs are considered to be the most critical aspect of economic growth in the developing world by improving national competition (Cruz-Cunha et al., 2010; KPMG, 2017). SMEs are always represented by the model of economic development due to a significant contribution to the domestic production, employment generations, low investment requirements, and significant export earnings, which together contributed to the nation's foreign exchange with low import intensive operations. The adoption of Cloud based BD provides ample opportunities to achieve a particular mixture of various resources of computing (that comprise of computers, storage devices, services, and software) through the Internet (Laudon \& Traver, 2014).

\subsection{Cloud based Big Data for Indian SMEs}

Data analytics can help E-commerce companies to analyze prices or products across multiple sites and come up with innovative promotions and pricing strategies to beat competitors. The digital revolution resulted in an astronomical growth of data due to ubiquitous smart devices and a socially connected platform. It resulted in companies better understanding customers' requirements by leveraging data generated at various touchpoints. India has more than 100,000 professionals involved in some way with data analytics, however most of these people work for foreign companies. Subsequently most of these 
people do not cater to Indian businesses. With the recent digital revolution supported by the government, India has 400 million internet subscribers, with an increase to 275 million smartphone users from 1 million cellphone users. This can help SMEs tremendously in gathering and analyzing data for business benefits (Menon, 2017). Interest in Cloud computing and Big Data is consistent in India for the last three year as shown in Figure 2 . Numbers represent search interest in relation to highest point on chart and value 100 is peak popularity for the term BD and CC.

\section{Interest in Cloud Computing and Big Data (India)}

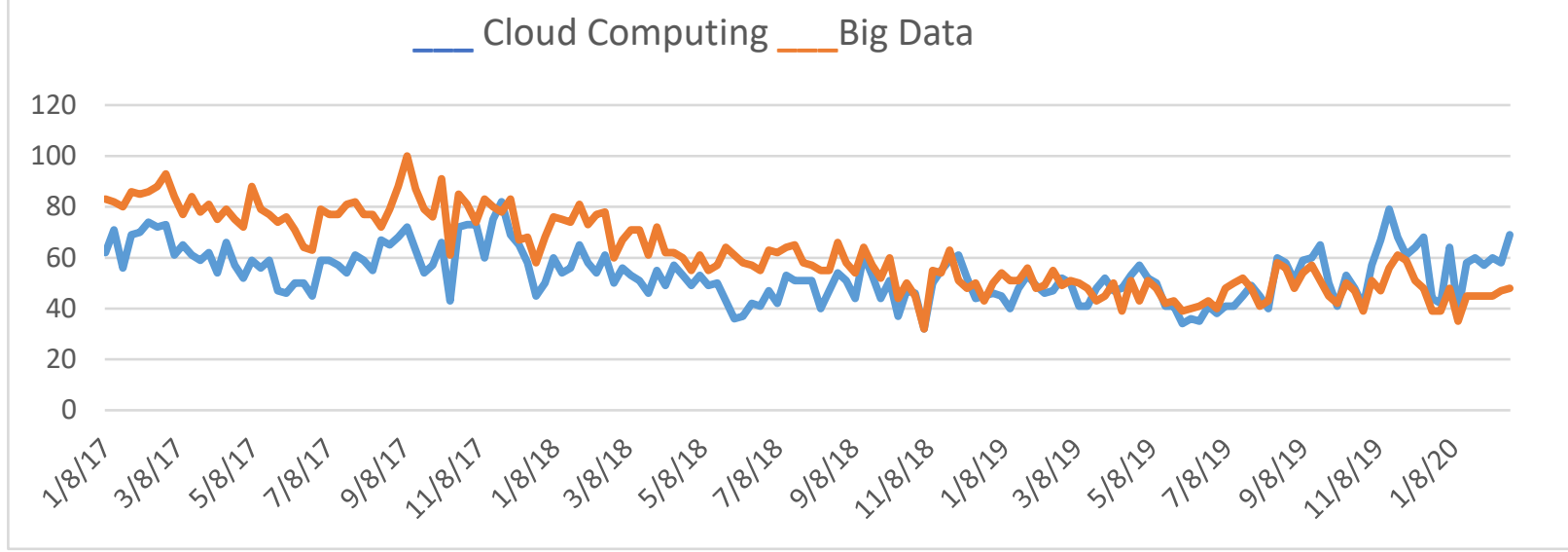

Figure 2: Data source: Google Trends (www.google.com/trends)

About thirty years ago, the use of data when it came to economic activities was comparatively scarce. Within a shorter duration, this notion has dramatically changed. The internet records everything that is being executed by human beings. Whenever one goes on Bing or Google, the questions and succeeding clicks or sites are often recorded (Rahi et al., 2017). According to Alsghaier et al. (2017), companies that collect data may use it to create new streams of revenue. The recording of a person's behavior does not stop with use of the internet: text messaging, cell phones as well as geo-locations, employment records, data scanners, and electronic health documents entail all data footprints, and are all recorded due to the introduction of big data techniques. The implementation of BD is broadly recognized by many businesses, which help to improve business operations (Wang, Kung, Wang, \& Cegielski, 2018).

Popovič, Hackney, Tassabehji, and Castelli (2016) argue that BD provide insights that allow business operation management and reinforce good relationships with customers. The scanners are capturing the appropriate time upon which a transaction happened, and histories of purchases made by a particular buyer. Retailers using the Internet are not only observing various information regarding the features of items sold but are also in a position to track the behaviors of consumers as sales are concerned. There has been corresponding evolution within various business activities with reference to big data (Popovič et al., 2016). Because companies have moved their daily processes to online platforms, it is becoming possible to compile data sets which are rich in sales contracts, practices of hiring, as well as physical goods shipments (Elgendy \& Elragal, 2014). It is imperative to note that big data has played a significant role in ensuring that business operations are greatly streamlined as per the current processes needed to reach the customers easily in the market. BD makes it possible for effective service delivery in companies, thus increasing sales (Rahi et al., 2017). 
The major aspect of BD is that they have much less structures compared to conventional cross-sectional, time-series based models for data panel, which are often taught in most of the econometric lessons (Dhabhai \& Gupta, 2016). If big data has been analyzed and distilled together with outdated enterprise data, then companies could be in a position to develop an in-depth understanding of their business (McAfee, Brynjolfsson, Davenport, Patil, \& Barton, 2012). This brings about increased productivity and a robust position of competitiveness alongside greater innovations.

The increase of GPS devices and smart phones provides opportunity for the advertisers to target clients whenever they are near stores, coffee shops or restaurants. This is opening up fresh revenues meant for service providers, as well as offering multiple chances for the business in targeting new customers for the products. Usually, retailers target the people who regularly buy their items. It is a resolution for analysing Big Data by deploying Big Data software like Hadoop on a Cloud background which gives users an innovative pattern of service called Analytics as a Service (Dhabhai \& Gupta, 2016). Social media use and files from weblogs attained from various sites of e-commerce assists them in comprehending the people who failed to buy the products and never made any purchases (Ogunrinde, Jusoh, Pa, Rahman, \& Abdullah, 2017). Such information assists retailers in improving their standard of service delivery. This might enhance much more operative segmentation of micro customers alongside various marketing campaigns targeted by an organization. In addition, this similarly assists in improving efficiencies in the supply chain via encouraging demand planning which is greatly more accurate (Singh, 2017). Lastly, social media sites such as Linkedln and Facebook simply could never exist when there is no big data technology. For that matter, big data technology is essential for the operation of most SME firms in India when it comes to increasing the companies' sales, and reaching out to customers, among others (Singh, 2017). According to Kalra (2016), new knowledge is gained from analysis data using data mining and machine learning, and data mining will be beneficial to SMEs while simply storing big chunks of data would not be sufficient. BD is key technology, which can help decision makers in SMEs access knowledge through data analytics, which was previously available to large organizations. However, BD analytics is a complex process demanding special skills required by staff and significant investment in the infrastructure required for the technology (Vajjhala \& Ramollari, 2016).

The BD environment requires server clusters to support the process which includes high volume, high velocity, and unstructured data. Cloud services deploy infrastructure as service (laaS) to scale up or down as required. CC can offer cost-effective ways to support BD technology and analytic application to provide business value. As CC grows, a number of organizations are building robust and efficient Cloud environments to provide services (Kalra, 2016).

\subsection{Big Data Opportunities and Challenges for Indian SMEs}

The potential utilization of big data in SME policies are roughly parallel to the usage within private sectors (Arunachalam, Kumar, \& Kawalek, 2017). Describing various data resources that are accessible to the government, as well as the ways in which most of the data from private sectors may be used to excellently track and predict economic activities highlight some of the opportunities witnessed in BD. In addition, the manner in which BD might be used towards providing essential information for policy makers within an organization similarly improves the functioning of SMEs. This also assists in the daily operations of this organization as their customers get the required information concerning products in the market instantly. The other opportunity for BD is making proper use of the data attained from the government for administrative usage. Through the functions of tax system administration, social 
programs, as well as regulations, the Indian government is tasked with the duty of collecting more massive amounts of various administrative data (Rahi et al., 2017). Examples of such data may incorporate datasets, which are rich micro-level information and are often maintained by government agencies. Even though there are lesser uniformities in such data, local and state government also generate a larger amount of data used for administrative purposes especially in areas of social insurance, education, as well as spending by the local government (Saa, Moscoso-Zea, Costales, \& LujánMora, 2017). Therefore, the use of such data in making economic policies for the SME firms in India appears to be helpful. The primary datasets similarly have the tendencies of being maintained separately by the users, which might involve merging datasets with individual demographics, employment, as well as some instances of matching them with the health data meant for the whole population (Ogunrinde et al., 2017). The government had restrictions sharing such information with SMEs and other private organizations resulting in limited access to data for decision-making.

SMEs who are wishing to take advantage of more massive datasets are facing multiple challenges (Verma \& Bhattacharyya, 2017). These may incorporate gaining accessibility to these datasets, creating programs for data management and capabilities required in working with bigger datasets, thinking of approaches to summarize their data, and describing as well as providing analysis for the contained information. Big Data analysis entails several different segments as indicated in Figure 3.

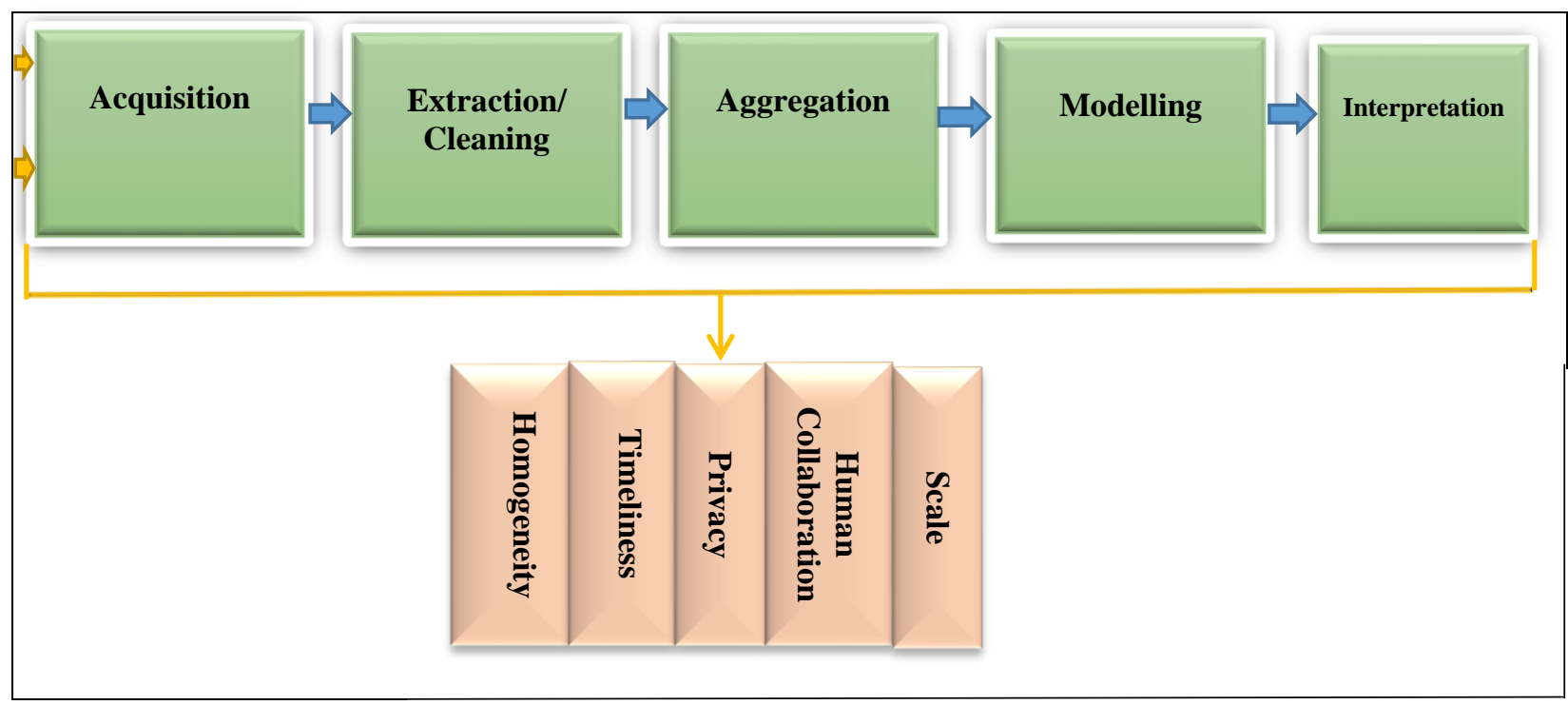

Figure 3 : Big data analysis challenges

Every phase introduces challenges that are likely to be experienced in each particular part. People inappropriately concentrate on merely the modelling or analysis stage; while the point is vital, it has little use when the other phases are not included for analysis. Homogeneity, timeliness, privacy, human coloration, and scale of data provide further challenges when adopting BD. SMEs do not have the resources to manage and analyze the scale of data available on the Internet, and timeliness of data is also required for better decision making. It also poses a challenge with homogeneity and privacy issues that are needed to be considered in order to adopt Cloud based BD. 
Even within the study that has attained more considerable attention, there are complexities that have been understood poorly within the perspective of multi-tenanted groups in which multiple programs for users often run concomitantly (Koul, Perikamana, Kumar, \& Kumar, 2017). Many serious challenges are extending past the phase of analysis. For instance, BD should be managed in the background so can data can be analyze using various upfront data analytical models. Doing so may raise the need for tracking attribution and handling uncertainties and errors; topics which are essential for the companies' achievement, and nevertheless hardly stated within the similar Big Data topics (Kshetri et al., 2017). In fact, most of the companies in India are having the major bottleneck when it comes to the number of people who are empowered in asking questions concerning data analysis. The number can be increased drastically through supporting multiple ranks of data engagement. This does not require expertise in data operations (Rahi et al., 2017). The solutions for various problems which have been attained shall never come from incremental improvements towards business. However, such enhancements need the users to reconsider ways in which data analysis should be managed fundamentally.

\section{RESEARCH METHODOLOGY}

The purpose of this article is analysis of Cloud based BD challenges and opportunities for SMEs in India. Three research questions were framed to assist in accomplishing this aim, as shown below.

\section{RQ1: What are the recent trends in the area of Cloud based BD in India? \\ RQ2: What are the opportunities for Indian SMEs in adopting Cloud based BD? RQ3: What are the challenges faced by Indian SMEs in adopting Cloud based BD?}

For this research, a comprehensive literature review of Cloud based service, BD, as well as BD and Cloud based service was conducted using online library databases. Several online databases such as EBSCO, IEEE, ACM Digital libraries, and Gale computer databases were used to search for relevant articles. To answer the first research question, some of the keywords used were "Cloud based adoption Indian SMEs", "recent trend of Cloud based BD adoption in India", "Challenges faced in adopting BD in developing country, "Benefits and opportunity for Indian SMEs adopting Cloud based BD".

The search was limited from 2015 to 2018, and some of the key articles that were cited for RQ1 include the work of Alsghaier et al. (2017), Egendry and Elragal (2014), Khan and Alam (2017) and Kshetri and Torres (2017). For the second and third question, articles related to Cloud based BD challenges and opportunities for SMEs in India were studied.

RQ2 involved identifying opportunities for Indian SMEs in adopting Cloud based BD. Several authors who identified opportunities were Rahi et al. (2017), Saa et al. (2017) and Cao (2017). Authors such as Veram and Bhatacharyya (2017), Gupta et al. (2017), Kumar et al (2017) and Priyadarshinee et al. (2017), identified some of the challenges associated with Cloud based BD adoption.

Some of the Journal papers that were studied to answer this research question included articles identifying the key enablers on how SMEs could innovate and grow. One of the key factors identified during this search was the use of new technologies by SMEs. Some of the researchers identified links between the use of novel technologies and innovation adopted in SMEs. However, resource constraints often inhibit SMEs from investing in new technologies. Cloud Computing technology could be a solution in cases such as SMEs, who can benefit from the low-cost solutions offered by Cloud providers and also do not have to invest in in-house solutions which are relatively expensive. RQ3 involved identifying some of the challenges faced by Indian SMEs in adopting Cloud based BD. Some of the challenges from the 
literature review were in the processes of data generation, acquisition, storage, and the analytics of big data. After these factors were identified, the study narrowed down to identifying the key factors that would be applicable from the perspective of SMEs, as shown in Table 1.

Table 1 Literature by keywords search in online Databases

\begin{tabular}{|c|c|c|c|c|}
\hline Keyword search & EBSCOhost & ProQuest & $\begin{array}{l}\text { IEEE } \\
\text { Explore }\end{array}$ & $\begin{array}{l}\text { Gale computer } \\
\text { database }\end{array}$ \\
\hline Big Data & 1575 & 1681 & 570 & 323 \\
\hline $\begin{array}{l}\text { Cloud based service/Cloud } \\
\text { Computing }\end{array}$ & 2481 & 2234 & 1300 & 1708 \\
\hline India SMEs using Big Data & 382 & 390 & 250 & 195 \\
\hline $\begin{array}{l}\text { Indian SMEs using Cloud } \\
\text { Computing }\end{array}$ & 453 & 467 & 371 & 300 \\
\hline $\begin{array}{l}\text { Big Data using Cloud based } \\
\text { service }\end{array}$ & 713 & 913 & 571 & 375 \\
\hline $\begin{array}{l}\text { Challenges using Cloud based Big } \\
\text { data }\end{array}$ & 413 & 409 & 512 & 317 \\
\hline $\begin{array}{l}\text { Opportunity using Cloud based } \\
\text { Big Data }\end{array}$ & 781 & 571 & 413 & 267 \\
\hline
\end{tabular}

\section{FUTURE RESEARCH AND LIMITATION}

The research methodology for this research paper focused on an extensive study of the literature via a keyword search pertaining to the research topic. Future research will focus on conducting surveys to identify key factors affecting Cloud based BD adoption for Indian SMEs. Online surveys based on research questions will be developed and sent to random SMEs using or planning to use Cloud based $\mathrm{BD}$ services. Future research will also look at the technological, organisational and environmental factors affecting Cloud based BD by Indian SMEs. In addition, this research extensively focused on Indian SMEs, while future research can focus on other developing economies and the impact on large organizations and government.

\section{CONCLUSION}

Globally, we have reached an era of Big Data. Data analysis of the vast amounts of accessible data can provide a competitive advantage to Indian SMEs in the global market. SMEs do not have a massive Information Communication Technology (ICT) department or budget. Hence, they do not have access to sophisticated IT architectures and supporting tools for decision making. Cloud based BD can provide many benefits to SMEs, such as access to customer data for better decision making. On the other hand, several technical challenges which have been outlined within this paper ought to be addressed before the potentiality of Cloud based BD is wholly realized. The problems might incorporate not only the apparent scale issues, but also heterogeneity, small structures, error-handling, privacies, and timeliness 
Sandu, N., Gide, E., Karim, S., (2020). A Comprehensive Analysis of Cloud based Big Data Challenges and Opportunities for SMEs in India. Global Journal of Information Technology: Emerging Technologies. 10(1), 35-44. DOI: 10.18844/gjit.v\%vi\%i.4745

alongside visualization, which happens at every stage of data analysis right from the acquisition of data up to the interpretation of results. This paper can help Cloud based BD service providers and government to formulate a policy and provide a solution which would help SMEs to avail better decision making at a lower cost.

\section{REFERENCES}

Alsghaier, H., Akour, M., Shehabat, I., \& Aldiabat, S. (2017). The Importance of Big Data Analytics in Business: A Case Study. American Journal of Software Engineering and Applications, 6(4), 111-115.

Alshamaila, Y., Papagiannidis, S., \& Li, F. (2013). Cloud computing adoption by sme's in the north east of england: a multi-perspective framework. Journal of Enterprise Information Management, 26(3), 4-4.

Arunachalam, D., Kumar, N., \& Kawalek, J. P. (2017). Understanding big data analytics capabilities in supply chain management: Unravelling the issues, challenges and implications for practice. Transportation Research Part E: Logistics and Transportation Review.

Bagozzi, R. P. (2007). The legacy of the technology acceptance model and a proposal for a paradigm shift. Journal of the association for information systems, 8(4), 3 .

Cruz-Cunha, M. M., Hauc, A., Perko, I., Mulej, M., Bobek, S., Sternad, S., \& Ženko, Z. (2010). Enterprise information systems for business integration in SMEs: technological, organizational, and social dimensions: Business Science Reference.

Dhabhai, A., \& Gupta, Y. K. (2016). A Study of Big Data in Cloud Environment with their Related Challenges. International Journal of Engineering Science, 2511.

Dua, H. s. (2017). Taking advantage of Big Data: A way forward to becoming big from small The Economic times. Retrieved from https://economictimes.indiatimes.com/small-biz/sme-sector/taking-advantage-of-big-dataa-way-forward-to-becoming-big-from-small/articleshow/58356383.cms

Elgendy, N., \& Elragal, A. (2014). Big data analytics: a literature review paper. Paper presented at the Industrial Conference on Data Mining.

Gide, E., \& Sandu, R. (2015). A Study to Explore the Key Factors Impacting on Cloud Based Service Adoption in Indian SMEs. Paper presented at the e-Business Engineering (ICEBE), 2015 IEEE 12th International Conference on.

Gupta, S., Misra, S. C., Singh, A., Kumar, V., \& Kumar, U. (2017). Identification of challenges and their ranking in the implementation of cloud ERP: A comparative study for SMEs and large organizations. International Journal of Quality \& Reliability Management, 34(7), 1056-1072.

Hashem, I. A. T., Yaqoob, I., Anuar, N. B., Mokhtar, S., Gani, A., \& Khan, S. U. (2015). The rise of "big data" on cloud computing: Review and open research issues. Information Systems, 47, 98-115.

Kalra, S. (2016). Cloud Computing for Big Data Analytics. International Journal of Engineering and Management Research (IJEMR), 6(3), 17-21.

Khan, S., \& Alam, M. (2017). On Designing a Generic Framework for Cloud-based Big Data Analytics. arXiv preprint arXiv:1711.04628.

Khan, S., Shakil, K. A., \& Alam, M. (2018). Cloud-Based Big Data Analytics-A Survey of Current Research and Future Directions. In Big Data Analytics (pp. 595-604): Springer.

Koul, S., Perikamana, H. N., Kumar, U., \& Kumar, V. (2017). Enhancing BRICS integration: a cloud-based green supply chain concept. International Journal of Information Technology and Management, 16(4), 317-332.

KPMG. (2017). Impact of internet and digitisation on SMBs in India. A study by KPMG in India and Google. Retrieved from https://assets.kpmg.com/content/dam/kpmg/in/pdf/2017/01/Impact-of-internet-anddigitisation.pdf

Kshetri, N., Fredriksson, T., \& Torres, D. C. R. (2017). Big Data and Cloud Computing for Development: Lessons from Key Industries and Economies in the Global South: Taylor \& Francis.

Kulesh, S. (2018). India tops Big Data and Analytics adoption in APAC region: Oracle. Bussiness Standard. Retrieved from http://www.business-standard.com/article/news-ians/india-tops-big-data-and-analyticsadoption-in-apac-region-oracle-118022400206_1.html

Laudon, K., \& Traver, G. (2014). E-commerce, Business enterprise, Technologies and Society. In: New Jersey: Pearson. 
Sandu, N., Gide, E., Karim, S., (2020). A Comprehensive Analysis of Cloud based Big Data Challenges and Opportunities for SMEs in India. Global Journal of Information Technology: Emerging Technologies. 10(1), 35-44. DOI: 10.18844/gjit.v\%vi\%i.4745

Lin, A., \& Chen, N.-C. (2012). Cloud computing as an innovation: Percepetion, attitude, and adoption. International Journal of Information Management.

McAfee, A., Brynjolfsson, E., Davenport, T. H., Patil, D., \& Barton, D. (2012). Big data: the management revolution. Harvard business review, 90(10), 60-68.

Mell, P., \& Grance, T. (2011). The NIST definition of cloud computing (draft). NIST special publication, 800(145), 7.

Menon, S. (2017). India's tryst with Big Data. http://www.tata.com/article/inside/big-data-india-deep-thomas. Retrieved from http://www.tata.com/article/inside/big-data-india-deep-thomas

MSME. (2017). Ministry of Micro Small and Medium enterprises- Annual report 2016-2017. Retrieved from India: https://msme.gov.in/sites/default/files/MSME\%20ANNUAL\%20REPORT\%20201617\%20ENGLISH.pdf

Ogunrinde, R. R., Jusoh, Y. Y., Pa, N. C., Rahman, W. N. W. A., \& Abdullah, A. (2017). QoS-Based Cloud ERP Selection Model for SMEs. Journal of Telecommunication, Electronic and Computer Engineering (JTEC), 9(2-4), 21-25.

Popovič, A., Hackney, R., Tassabehji, R., \& Castelli, M. (2016). The impact of big data analytics on firms' high value business performance. Information Systems Frontiers, 1-14.

Priyadarshinee, P., Raut, R. D., Jha, M. K., \& Kamble, S. S. (2017). A cloud computing adoption in Indian SMEs: Scale development and validation approach. The Journal of High Technology Management Research, 28(2), 221-245

Rahi, S. B., Bisui, S., \& Misra, S. C. (2017). Identifying the moderating effect of trust on the adoption of cloudbased services. International Journal of Communication Systems, 30(11).

Rohani, M. B., \& Hussin, A. R. C. (2015). An integrated theoretical framework for cloud computing adoption by universities technology transfer offices (TTOs). Journal of Theoretical and Applied Information Technology. 79 ppp, 415-430.

Saa, P., Moscoso-Zea, O., Costales, A. C., \& Luján-Mora, S. (2017). Data security issues in cloud-based Softwareas-a-Service ERP. Paper presented at the Information Systems and Technologies (CISTI), 2017 12th Iberian Conference on SRC.

Sandu, R., Gide,E.,Karim,S. (2017). An Analysis of SMEs Customer Behavior in Cloud-Based E-commerce Environment Academic Journal of Science, 7(2), 281-292. doi:07(02):281-292 (2017)

Sandu, R. G., E.,Karim,S. (2017). The Impact of Innovative Strategies to Influence the Adoption of Cloud Based Service Success in Indian Small and Medium Enterprises (SMES). International Journal of Arts \& Sciences, $\quad$ 10(2), 389-399. Retrieved from http://www.universitypublications.net/ijas/1002/html/P7RS180.xml

Sharma, S. K., Al-Badi, A. H., Govindaluri, S. M., \& Al-Kharusi, M. H. (2016). Predicting motivators of cloud computing adoption: A developing country perspective. Computers in Human Behavior, 62, 61-69. doi:10.1016/j.chb.2016.03.073

Singh, J. (2017). Study on Challenges, Opportunities and Predictions in Cloud Computing. International Journal of Modern Education and Computer Science, 9(3), 17.

Sivarajah, U., Kamal, M. M., Irani, Z., \& Weerakkody, V. (2017). Critical analysis of Big Data challenges and analytical methods. Journal of Business Research, 70, 263-286.

Vajjhala, N. R., \& Ramollari, E. (2016). Big data using cloud computing-opportunities for small and medium-sized enterprises. European Journal of Economics and Business Studies, 4(1), 129-137.

Verma, S., \& Bhattacharyya, S. S. (2017). Perceived strategic value-based adoption of Big Data Analytics in emerging economy: A qualitative approach for Indian firms. Journal of Enterprise Information Management, 30(3), 354-382.

Wang, Y., Kung, L., Wang, W. Y. C., \& Cegielski, C. G. (2018). An integrated big data analytics-enabled transformation model: Application to health care. Information \& Management, 55(1), 64-79.

Zolkepli, I. A., \& Kamarulzaman, Y. (2015). Social media adoption: The role of media needs and innovation characteristics. Computers in Human Behavior, 43, 189-209. 